\title{
Comparison of three obturation techniques with regard to bacterial leakage
}

\author{
Cleber Keiti Nabeshima1, Guilherme Henrique Rosa Martins', Mário Francisco de Pasquali Leonardo', \\ Regina Célia Furukava Shin', Silvana Cai ${ }^{2}$, Manoel Eduardo de Lima Machado ${ }^{1}$
}

\author{
1Department of Restorative Dentistry, School of Dentistry, University of São Paulo, São Paulo, SP, Brazil \\ ${ }^{2}$ Department of Microbiology, Professor, Institute of Biomedical Science, University of São Paulo, São Paulo, SP, Brazil
}

Received for publication: August 05, 2013 Accepted: September 11, 2013

Corrrespondence to: Cleber K. Nabeshima Av. Prof. Lineu Prestes, 2227 Cidade Universitária CEP: 05508-000, São Paulo, SP, Brasil Phone: +5511982244330 E-mail: cleberkn@ hotmail.com

\begin{abstract}
Aim: To compare bacterial leakage in root canals obturated with the modified single-cone, lateral condensation, and continuous wave of condensation techniques. Methods: Distobuccal root canals of maxillary molars were shaped up to ProTaper F2 and obturated with modified singlecone, lateral condensation or continuous wave of condensation technique. Two-chamber bacterial model using Enterococcus faecalis was employed for bacterial leakage evaluation for 30 days. The chi-square test was applied to evaluate differences between turbid and non-turbid samples, and the Kruskal-Wallis test was used for evaluating the time necessary for microleakage. A significance level of $5 \%$ was set for all analyses. Results: The modified single-cone technique showed leakage in $73.3 \%$ of samples, lateral condensation in $66.6 \%$, and continuous wave of condensation in $53.3 \%$, but there were no significant differences among the groups $(p>0.05)$. Conclusions: It can be concluded that the modified single-cone technique shows similar sealing efficacy to that of lateral condensation and continuous wave of condensation technique.
\end{abstract}

Keywords: dental leakage, Enterococcus faecalis, root canal obturation.

\section{Introduction}

The goal of the obturation of a root canal system is its sealing through the binding of a solid material with an endodontic sealer. However, it has been observed that excessive sealer can be solubilized and create empty spaces, hampering the sealing ${ }^{1}$.

Lateral condensation is the oldest and still used technique, but it requires professional expertise and demands more time and material for its execution ${ }^{2}$. The thermoplasticized gutta-percha root canal obturation technique is one the most indicated because it is associated with better anatomic filling ${ }^{3-4}$ and less quantity of sealer used ${ }^{5-7}$, but it lacks longitudinal control and needs special equipment ${ }^{3}$.

In this way, the improvement of older and conventional techniques is aimed at enhancing practicality, rapidity and simplicity, which benefit both the patient and the dentist. Currently, even shaping of the canal walls is achieved by mechanized instrumentation, which allows single-cone root filling. This obturation technique does not need the introduction of many accessory cones ${ }^{2}$, reduces the operating time ${ }^{8}$, is easy to perform, and does not require special equipment.

However, it has been observed that shaping with ProTaper rotary system allows the use of a 0.06 master cone and an apical diameter larger than the last instrument, characterizing this as a modified single-cone technique ${ }^{9}$. Comparisons of the amount 
of filling material between the original ProTaper single-cone and modified single-cone showed a greater percentage of gutta-percha in relation to sealer when utilizing the modified technique ${ }^{10}$.

Considering that there are no studies evaluating the sealing ability of the single-cone modified technique, the aim of the present study was to compare the microleakage of canals instrumented with ProTaper and obturated by the modified single-cone technique, lateral condensation, and continuous wave of condensation.

\section{Material and methods}

After approval of Ethics Committee of the School of Dentistry, University of São Paulo (23/2010), 49 distobuccal roots of maxilary molars were standardized to $10 \mathrm{~mm}$ in length and sterilized in an autoclave. The canal pathway was explored and the apical foramen was standardized using a size $15 \mathrm{~K}$-file (Dentsply Maillefer, Ballaigues, Switzerland).

The specimens were instrumented according to Machado et al. ${ }^{9}$ : the cervical and middle thirds were prepared with Gates Glidden 1, 2 and 3 drills (Dentsply Maillefer,) and ProTaper (Dentsply Maillefer) SX and S2 files at $500 \mathrm{rpm}$ and torque of $4 \mathrm{Ncm}$ (X-Smart; Dentsply Maillefer). The working length was determined using a size $15 \mathrm{~K}$-file introduced to less than $1 \mathrm{~mm}$ from the foramen. The apical third was instrumented with manual files up to size $25 \mathrm{~K}$-file followed by ProTaper S1, S2, F1, and F2, using $1 \% \mathrm{NaOCl}$ (Fórmula e Ação, São Paulo, SP, Brazil). The final irrigation was done with $5 \mathrm{~mL}$ of $1 \% \mathrm{NaOCl}$ followed by $5 \mathrm{~mL}$ of $17 \%$ EDTA (Fórmula e Ação) and then another $5 \mathrm{~mL}$ of $1 \% \mathrm{NaOCl}$. After verification of patency with a size $15 \mathrm{~K}$-file, the canals were dried with paper points (ProTaper; Dentsply Maillefer).

Specimens were randomly divided into 3 groups $(n=15)$ as follows:

Modified single-cone: a 30 or 35/0.06 master cone (Dentsply Maillefer) (which achieved a better fit in the working length) was placed in the canal with AHPlus sealer (Dentsply De Trey Gmbh, Konstanz, DE-BW, Germany) prepared as recommended by the manufacturer. Gutta-percha excess was removed with an electric plugger (Dentsply Tulsa Dental, Tulsa, OK, United States of America) set at $200^{\circ} \mathrm{C}$, followed by cold condensation.

Lateral condensation: a 30 or 35/0.02 master cone (which provided better fit in the working length) was selected and placed in the canal with AHPlus sealer. Lateral compaction was achieved by using accessory cones (Dentsply Maillefer) and finger spreader B (Dentsply Maillefer) until they did not penetrate more than $2 \mathrm{~mm}$ of the cervical third. The excess was removed and condensed as in the preceding group.

Continuous wave of condensation: a 0.02 master cone was selected and placed in the canal as in the preceding groups, where it was placed in the canal with AHPlus sealer. An electric plugger set at $200^{\circ} \mathrm{C}$ and previously calibrated to $6 \mathrm{~mm}$ was introduced in the canal, and cold condensation was performed in the apical third. Backfilling was then carried out using the Calamus Pack Obturation Delivery System (Dentsply Tulsa Dental, Tulsa, OK, USA) set at $180^{\circ} \mathrm{C}$, followed by cold condensation.

The positive control consisted of two specimens instrumented and with no obturation, and the negative control consisted of two specimens in which lateral condensation was used for obturation and the coronal opening sealed with cyanoacrylate (Henkel, Jacareí, SP, Brazil) ${ }^{11}$.

Two layers of cyanoacrylate adhesive were applied to the outer surface of the root, leaving $2 \mathrm{~mm}$ of the apex free. All specimens were placed in an incubator at $37^{\circ} \mathrm{C}$ with $100 \%$ humidity for 7 days.

Forty-nine capped acrylic vials were used. The center of the cap was perforated for fitting an Eppendorf microtube (Axygen, Union City, CA, USA) with tip removed. The root was fitted to the Eppendorf, and fixed with cyanoacrylate. Sealing was done using a double layer of fingernail polish (Impala, Porto Velho, RO, Brazil), a layer of epoxy (Araldite, Brascola, Joinvile, SC, Brazil) and another two layers of fingernail polish.

The apparatus was sterilized with ethylene oxide, and 3 $\mathrm{mL}$ of sterile TSB (Tryptic Soy Broth, Difco, Le Pont de Claix, RA, France) were introduced in the acrylic vial, with $2 \mathrm{~mm}$ of the root apex immersed in the solution. The apparatus was incubated at $37^{\circ} \mathrm{C}$ for 7 days to demonstrate sterility.

A sample of Enterococcus faecalis (ATCC 29212) in TSB was standardized to a McFarland scale of 4 (BioMèriex, Marcy-l'Etoile, RA, France), and added to the upper reservoir.

The apparatus was incubated at $37^{\circ} \mathrm{C}$, and every $48 \mathrm{~h}$, $200 \mu \mathrm{L}$ of the bacterial broth were removed and $200 \mu \mathrm{L}$ of fresh TSB were added. TSB in the lower reservoir was checked for turbidity.

After an experimental period of 30 days, $100 \mu \mathrm{L}$ of the broth in the upper compartment of the specimens showing no leakage and of the negative control group were collected and added to TSB of the lower compartment, followed by incubation at $37^{\circ} \mathrm{C}$ for $24 \mathrm{~h}$ to demonstrate cell viability. To confirm the purity of $E$. faecalis in TSB, a sample of broth in the lower reservoir of the specimens showing leakage and of the positive control group were cultivated on TSA (Tryptic Soy Agar, Difco, Le Pont de Claix, RA, France) plates and the colony morphology and cellular characteristics were observed.

The chi-square test was applied to evaluate differences between turbid and non-turbid samples, and the KruskalWallis test was used for evaluating the time necessary for the occurrence of microleakage. The significance level was set at $5 \%$ for all analyses.

\section{Results}

The positive control group specimens showed turbidity within $24 \mathrm{~h}$ of incubation.

On the 30th day, most of the samples showed leakage, with no significant difference between the groups $(p<0.05)$. The distribution of samples leaked and non-leaked is shown in Table 1. 
Table 1. Samples with leakage or not at 30 days

\begin{tabular}{llll}
\hline Groups $^{\star}$ & $\mathbf{n}$ & Leakage & Non-leakage \\
Modified Single-Cone & 15 & $11(73.3 \%)$ & $4(26.7 \%)$ \\
Lateral Condensation & 15 & $10(66.6 \%)$ & $5(33.4 \%)$ \\
Continuous wave of condensation & 15 & $8(53.3 \%)$ & $7(46.7 \%)$ \\
\hline Total & 45 & $29(64.4 \%)$ & $16(35.6 \%)$ \\
\hline
\end{tabular}

${ }^{*}$ Fisher's exact test, no significant difference $(p>0.05)$

The minimal time for turbidity was 10 days, whereas the mean time in the experimental period was 21.86 days, with no significant difference among the groups $(p=0.2817)$ (Table 2).

The negative control group did not show turbidity in the experimental period. Every sample not showing leakage had cell viability positively confirmed after experimental time.

\section{Discussion}

Various methods have been employed in the evaluation of the obturation of root canals: dye leakage ${ }^{12-13}$, fluid filtration $^{14-16}$, and bacterial leakage $\mathrm{e}^{17-24}$. The option for bacterial leakage is justified since it is an experimental model that is simple and easy to replicate. Besides, dye molecules are much smaller than bacteria, and the method of fluid filtration is overly sensitive.

Most studies have used single-rooted teeth ${ }^{17-24}$. The use of molars was proposed due to their high incidence in endodontic treatment, and the choice of the distobuccal root of the maxillary molar was based on a standardization criterion ${ }^{9}$.

Various bacteria have been used in microleakage studies $^{17-18,21,25}$. However, there is a focus on E. faecalis because of its resistance ${ }^{19-20,22,24}$, survival in nutrient-poor areas over long periods ${ }^{26}$, and association with persistent chronic periapical lesions ${ }^{27}$.

The results demonstrated that the mean time of leakage in samples in the experimental period was 21 days. The first sample showed leakage at 10 days, and $64.4 \%$ showed leakage within the experimental time. Even though the thermoplasticized group showed a larger number of specimens without leakage, there was no significant difference among the groups in relation to the number of samples with leakage or not, and to the time necessary for microleakage. However, these results should be interpreted with caution. Although this method is the most used, the results differ and do not reproduce the high rate of clinical success of endodontic treatments. The findings of the present study show a similar high rate of leakage as in different experimental works ${ }^{17,19,21-23}$. However, we agree with Baumgartner et al. ${ }^{20}$ (2007) that these methods have limitations and the interpretation of the results is interesting for comparisons between among, although they do not necessarily correspond to clinical reality. Furthermore, it is necessary to consider the absence of coronal restoration in this methodology that increases the rate of leakage. Thus, our results showed similar sealing ability of the techniques, but the microleakage could be less clinically due to coronal restoration ${ }^{28}$.

The comparison of our results to other studies is hampered because many methodological variables can be seen; such as the experimental period. The literature demonstrates a discrepancy between the studies that showed a high rate of microleakage in the short-term and those that showed a lower percentage of samples with leakage in the long-term. For example, Jacobson et al. ${ }^{17}$ (2002) showed $75 \%$ of samples with lateral condensation with leakage at 48 days, Yücel and Çiftçi ${ }^{19}$ (2006) with $95 \%$ at 60 days, Ta ${ }^{\circ}$ demir et al. ${ }^{22}$ (2009) with $45 \%$ at 56 days, Nawal et al. ${ }^{23}$ (2011) with $70 \%$ at 30 days, Kangarlou et al. ${ }^{24}$ (2012) with $93 \%$ at 60 days, and the present study with $66.6 \%$ at 30 days. In contrast, De-Deus et al. ${ }^{18}$ (2006) found $16 \%$ at 100 days, and De-Deus et al. ${ }^{25}$ (2008) with $30 \%$ at 105 days. Another variable that should be noted is the length of roots. Monticelli et al. ${ }^{21}$ (2007) used samples measuring $17 \mathrm{~mm}, \mathrm{Ta}^{\mathrm{o}}$ demir et al. ${ }^{22}$ (2009) $16 \mathrm{~mm}$, and Nawal et al. ${ }^{23}$ (2011) $15 \mathrm{~mm}$, compared to $10 \mathrm{~mm}$ in the present study. Also adding to the variables are other conditions such as different groups of teeth, sealers and bacterial species.

Even with the above-mentioned methodological questions, this is the in vitro method most currently accepted by the scientific community. In view of the results, the similarity among the experimental groups indicates the modified single-cone technique as an alternative that achieves the objectives of rapidity, practicality and simplicity, without loss of quality in relation to the conventional techniques. However, future studies should be conducted aimed at searching for new assessment methods that can produce results with less significant differences between experimental models.

\section{Acknowledgments}

The authors thank ACECIL Ltda. for providing the ethylene oxide sterilization, Dentsply-maillefer and Fórmula \& Ação for supplying materials, and Dr. A. Leyva helped with the translation of the manuscript.

Table 2. Values with respect to the time necessary (in days) for microleakage

\begin{tabular}{llllllll}
\hline Groups $^{*}$ & $\mathbf{n}$ & Min & Max & Med & IR & SD & Mean \\
Modified Single-Cone & 15 & 11 & +30 & 21 & 17 & 8.26 & 20.73 \\
Lateral Condensation & 15 & 10 & +30 & 18 & 18 & 8.34 & 20.06 \\
Continuous wave & 15 & 11 & +30 & 30 & 9 & 7.33 & 24.66
\end{tabular}

of condensation

$\mathrm{n}$ - Number of the specimens; Min - Minimum; Max - Maximum; Med - Median;

IR - Interquartile Range; SD - Standard Deviation

${ }^{*}$ Kruskal-Wallis test, no significant difference $(p>0.05)$ 


\section{References}

1. Peters DD. Two-year in vitro solubity evaluation of four gutta-percha sealer obturation techniques. J Endod. 1986; 12: 139-45.

2. Hembrough MW, Steiman HR, Belanger KK. Lateral condensation in canals prepared with nickel titanium rotary instruments: an evaluation of the use of three different master cones. J Endod. 2002; 28: 516-9.

3. Gabardo MCL, Silva WJ, Gonçalves LM, Deonízio MDA. Effectiveness of different obturation techniques in surpassing the ledge formed in simulated curved canals. Braz J Oral Sci. 2013; 12: 138-42.

4. Yelton C, Walker MP, Lee C, Dryden JA, Kulild JC. Assessment of a thermoplasticized gutta-percha delivery system to effectively obturate canals with varying preparation dimensions. J Endod. 2007; 33: 156-9.

5. Ozawa T, Taha N, Messer HH. A comparison of techniques for obturating oval-shaped root canals. Dent Mat J. 2009; 28: 290-4.

6. Somma F, Cretella G, Carotenuto M, Pecci R, Bedini R, De Biasi M, et al. Quality of thermoplasticized and single point root fillings assessed by microcomputed tomography. Int Endod J. 2011; 44: 362-9.

7. Marciano MA, Ordinola-Zapata R, Cunha TVRN, Duarte MAH, Cavenago $\mathrm{BC}$, Garcia RB, et al. Analysis of four gutta-percha techniques used to fill mesial root canals of mandibular molars. Int Endod J. 2011; 44: 321-9.

8. Gordon MPJ, Love RM, Chandler NP. An evaluation of .06 tapered guttapercha cones for filling of .06 taper prepared curved root canals. Int Endod J. 2005; 38: 87-96.

9. Machado MEL, Sapia LAB, Cai S, Martins GHR, Nabeshima CK. Comparison of two rotary systems in root canal preparation regarding disinfection. J Endod. 2010; 36: 1238-40.

10. Araquam KR, Britto MLB, Nabeshima CK. Comparison of two single-cone obturation techniques. Endo (Lond Engl). 2011; 5: $133-7$.

11. Rechenberg D-K, De-Deus G, Zehnder M. Potential systematic error in laboratory experiments on microbial leakage through filled root canals: review of published articles. Int Endod J. 2011; 44: 183-94.

12. Gilhooly RMP, Hayes SJ, Bryant ST, Dummer PMH. Comparison of lateral condensation and thermomechanically compacted warm á-phase guttapercha with a single cone for obturating curved root canals. Oral Surg Oral Med Oral Pathol Oral Radiol Endod. 2001; 91: 89-94.

13. Zmener $\mathrm{O}$, Pameijer $\mathrm{CH}$, Macri $\mathrm{E}$. Evaluation of the apical seal in root canals prepared with a new rotary system and obturated with a methacrylate based endodontic sealer: an in vitro study. J Endod. 2005; 31: 392-5.

14. Machado R, Silva Neto UX, Ignácio SA, Cunha RS. Lack of correlation between obturation limits and apical leakage. Braz Oral Res. 2013; 27:331-5.

15. Monticelli F, Sword J, Martin RL, Schuster GS, Weller RN, Ferrari M, Pashley DH, Tay FR. Sealing properties of two contemporary single-cone obturation system. Int Endod J. 2007; 40: 374-85.

16. Vasconcelos BC, Bernardes RA, Duarte MAH, Bramante CM, Moraes IG. Apical sealing of root canal fillings performed with five different endodontic sealers: analysis by fluid filtration. J Appl Oral Sci. 2011; 19: 324-8.

17. Jacobson HLJ, Xia T, Braumgartner JC, Marshall G, Beeler WJ. Microbial leakage evaluation of the continuous wave of condensation. J Endod. 2002; 28: 269-71.

18. De-Deus G, Murad CF, Reis CM, Gurgel-Filho E, Coutinho Filho T. Analysis of the sealing ability of different obturation techniques in oval-shaped canals: a study using a bacterial leakage model. Braz Oral Res. 2006; 20: 64-9.

19. Yücel AÇ, Çiftçi A. Effects of different root canal obturation techniques on bacterial penetration. Oral Surg Oral Med Oral Pathol Oral Radiol Endod. 2006; 102: e88-92.

20. Baumgartner $G$, Zehnder $M$, Paqué $F$. Enterococcus faecalis type strain leakage through root canals filled with gutta percha/AH Plus or Resilon/ Epiphany. J Endod. 2007; 33: 45-7.

21. Monticelli F, Sadek FT, Schuster GS, Volkmann KR, Looney SW, Ferrari $\mathrm{M}$, et al. Efficacy of two contemporary single-cone filling techniques in preventing bacterial leakage. J Endod. 2007; 33: 310-3.
22. Ta-demir T, Er K, Yildirim T, Buruk K, Çelik D, Cora S, et al. Comparison of the sealing ability of three filling techniques in canals shaped with two different rotary systems: A bacterial leakage study. Oral Surg Oral Med Oral Pathol Oral Radiol Endod. 2009; 108: e129-34.

23. Nawal RR, Parande M, Sehgal R, Rao NR, NaikA. A comparative evaluation of 3 root canal filling systems. Oral Surg Oral Med Oral Pathol Oral Radiol Endod. 2011; 111: 387-93.

24. Kangarlou A, Dianat O, Esfahrood ZR, Asharaf H, Zandi B, Eslami G. Bacterial leakage of GuttaFlow-filled root canals compared with Reasilon/ Epiphany and Gutta-percha/AH26- filled root canals. Aust Endod J. 2012; 38: 10-3.

25. De-Deus G, Murad C, Paciornik S, Reis CM, Coutinho-Filho T. The effect of the canal-filled area on the bacterial leakage of oval-shaped canals. Int Endod J. 2008; 41: 183-90.

26. Sedgley CM, Lennan SL, Appelbe OK. Survival of Enterococcus faecalis in root canals ex vivo. Int Endod J. 2005; 38: 735-42.

27. Gomes BPFA, Pinheiro ET, Jacinto RC, Zaia AA, Ferraz CCR, SouzaFilho FJ. Microbial analysis of canals of root-filled teeth with periapical lesions using Polymerase Chain Reaction. J Endod. 2008; 34: 537-40.

28. Siqueira Jr JF, Rôças IN, Alves FRF, Campos LC. Periradicular status related to the quality of coronal restorations and root canal fillings in a Brazilian population. Oral Surg Oral Med Oral Pathol Oral radiol Endod. 2005; 100: 369-74. 